\title{
A constant-speed penetrometer for high-resolution snow stratigraphy
}

\author{
Martin Sahneebeli, ${ }^{1}$ Jerome B. Johnson ${ }^{2}$ \\ ${ }^{1}$ Swiss Federal Institute for Snow and Avalanche Research, CH-7260 Davos Dorf, Switzerland \\ ${ }^{2}$ Cold Regions Research and Engineering Laboratory, U.S. Army Corps of Engineers, P.O. Box 35170, Fort Wainwright, AK 99703-0170, U.S.A.
}

\begin{abstract}
A new constant-speed penetrometer for field and laboratory measurements has been developed. The initially independent work of SFISAR and CRREL has been brought together, and a portable field device is now in an advanced stage of testing. The new penetrometer has high rigidity and a high-resolution large dynamic range force sensor. It uses a much smaller sensing head $(5 \mathrm{~mm})$ than previous designs and has a constant-speed drive. With this construction, the penetration resistance of very fine layers and the influence of the bonding strength between snow grains can be more accurately determined than is possible with the rammsonde or Pandalp. Artificial foam layers as thin as $2 \mathrm{~mm}$ and thin layers in snow have been detected by the penetrometer. Thin snow layers detected from penetration-resistance profiles have been correlated to fine layering as determined from plane-section microphotographs of samples taken adjacent to the profile. The instrument's measurements are highly repeatable and the lack of subjective decisions when operating the penetrometer makes the penetration resistance a quantitative measure of snow stratigraphy.
\end{abstract}

\section{INTRODUGTION}

The detection and classification of snow layers are most important in interpreting the snow cover. R. Haefeli (in Bader and others, 1954) invented the first penetrometer to simplify the time-consuming task of digging snow profiles and to gain insight into spatial variability. The rammsonde (also called Swiss Rammsonde or Haefeli Sonde), was developed from penetrometers used in soil mechanics. The cone has a diameter of $40 \mathrm{~mm}$ with a $60^{\circ}$ included angle. Haefeli recognized, however, that while the rammsonde can provide some characterization of the mechanical properties, it is unable to detect the thin layers often responsible for the formation of avalanches (R. Haefeli; in Bader and others, 1954). While other penetrometers have been developed, the rammsonde is the only instrument designed to measure an index of the snow mechanical properties that has wide acceptance and use.

Bradley (1966) invented the snow resistograph. This instrument uses an upward working snow blade and records the resistance force values on paper. The angle of the blade is not specified, the surface area is $6.7 \mathrm{~cm}^{2}$. St. Lawrence and Bradley (1973) compared the snow resistograph to the ram penetrometer. They found a good correlation between these instruments and could demonstrate a much better resolution of weak layers than was possible with the rammsonde. The resistograph has not been used widely, probably because of the complicated mechanical action and the limited maximal force range. Gubler (1975) examined the rammsonde critically, and proposed several improvements. He demonstrated that there is a good correlation between the tensile strength of homogeneous artificial snow and rammsonde resistance. The problem of an insufficient vertical resolution to detect thin layers was not solved and the proposed improvements were not implemented in newer rammsondes. Dowd and Brown (1986) developed the digital resistograph. This instrument records the force every $0.5 \mathrm{~cm}$, which is insufficient to detect thin layers that are often less than a few millimeters thick (Föhn, 1993). Brown and Birkeland (1990) described a more developed prototype, which could down-load data to a computer. Its force sensor and the electronics, however, lacked durability. No further development of the penetrometer has been undertaken. Schaap and Föhn (1987) tested a penetrometer developed from a commercial geotechnical instrument. The diameter of the cone was $11.3 \mathrm{~mm}$ with a $60^{\circ}$ included angle. The depth resolution was $1 \mathrm{~mm}$ and it recorded on a chart recorder. The instrument showed a very fine resolution especially of the harder layers. Some of the layers could not be found by classical analysis by hand, making signal interpretation difficult. Additionally, the cone diameter is still too large to detect thin layers. No further development of this instrument has been undertaken. Abe (1991) combined multiple sensors into one instrument in an attempt to characterize the snow pack stratigraphy. The published measurements are not correlated to a reference. Vogel (1995) used a very small diameter cone tip embedded in a thicker rod with a force transducer. No reliable measurements or comparisons have been conducted with this instrument. A commercial soil penetrometer with a dynamic impact (hammering) was adapted to the usual rammsonde (Navarre and others, 1994). This instrument shows a better spatial resolution than the conventionally battering rammsonde, because the depth measurement and energy-impact calculation are automatically processed. The instrument's ability to resolve thin layers and information about the snow microstructure is limited by the size of the cone.

These instruments all suffer from the same limitation in 
that the measured penetration resistance is not easily interpreted or correlated uniquely to other standard mechanical tests, either compressive, tension or shear. All penetrometers used in snow can therefore only be indicative of a normal mechanical property. Good correlations between penetration resistance and mechanical properties have been found for soils (Meigh, 1987). Fukue (1979) showed that the penetration force of a small blade penetrometer was highly correlated to the unconfined compressive strength of snow. Huang and others (1993) showed that micromechanical processes strongly affect penetration resistance in granular material. These findings support the proposition that thinblade and small-diameter penetrometers can better detect the microstructural character of snow than can large-diameter cone penetrometers and, as a consequence, should be well correlated to the macro-scale mechanical properties.

During the past 3 years, Johnson and Schneebeli (1997) worked independently to develop a penetrometer with high spatial resolution that could detect fine layering and microstructural effects. Their independent efforts have been combined to further develop the instrument and to correlate the penetrometer resistance measurements to well-defined mechanical properties. The fundamental concept is that a continuously recording small-diameter or thin-blade penetrometer will make a more direct connection to the micromechanical properties than do large-diameter cone penetrometers. Hence, the measurement of thin layers and structural properties of snow should be improved. Several tests have been made using a prototype penetrometer to prove the concept.

\section{DESIGN REQUIREMENTS AND EXPERIMENTAL EVALUATION OF THE PENETROMETER}

The snow penetrometer is designed to fulfill several requirements to minimize errors and interpretation ambiguities. The penetrometer should have a high rigidity and a constant penetration velocity. The measuring tip should have a small diameter (cone) or thickness (blade) and small length dimensions to allow detection of thin layers and the breaking of grain bonds rather than producing a primarily compressive failure. The depth of penetration should be at least $1.5 \mathrm{~m}$ to profile a normally deep snowpack. In addition, it should also be a field-portable device. High rigidity and constant velocity penetration minimize measurement inaccuracies that arise from the storage and release of energy during penetration and inertial forces caused by sudden penetration velocity changes. Constant-velocity penetration $\left(1-40 \mathrm{~mm} \mathrm{~s}^{-1}\right)$ avoids the rate-dependence associated with creep deformation. So far is no evidence of inertial forces in our records to date. Thin layers, either buried surface hoar, sun- or windcrusts, have typical vertical dimensions of between 3 and $10 \mathrm{~mm}$. The measuring tip must therefore be of a similar or smaller vertical dimension than these layers.

The prototype penetrometer built at SFISAR is shown in Figure 1. A geared drive rod (diameter $18 \mathrm{~mm}$ ) driven by a stepper motor is used to push a $5 \mathrm{~mm}$ diameter cone with a $90^{\circ}$ included angle-sensing tip into the snow. The sensing tip is connected to a force transducer housed in a cone mounted on the end of the drive rod through a $3 \mathrm{~mm}$ rod. The motor and the force transducer are controlled by custom-made electronics and a computer. The penetration velocity was $30 \mathrm{~mm} \mathrm{~s}^{-1}$ and measurements were made every one-third of https://doi.org/10.3189/1998AoG26-1-107-111 Published online by Cambridge University Press 108 a millimeter to provide high spatial resolution, which corresponds to a data-acquisition rate of $90 \mathrm{~Hz}$. The force transducer is a small-dimension piezoresistive quartz sensor with a large measurement range $( \pm 500 \mathrm{~N}$, resolution better than $0.02 \mathrm{~N}$ ) (Johnson and Schneebeli, 1997)

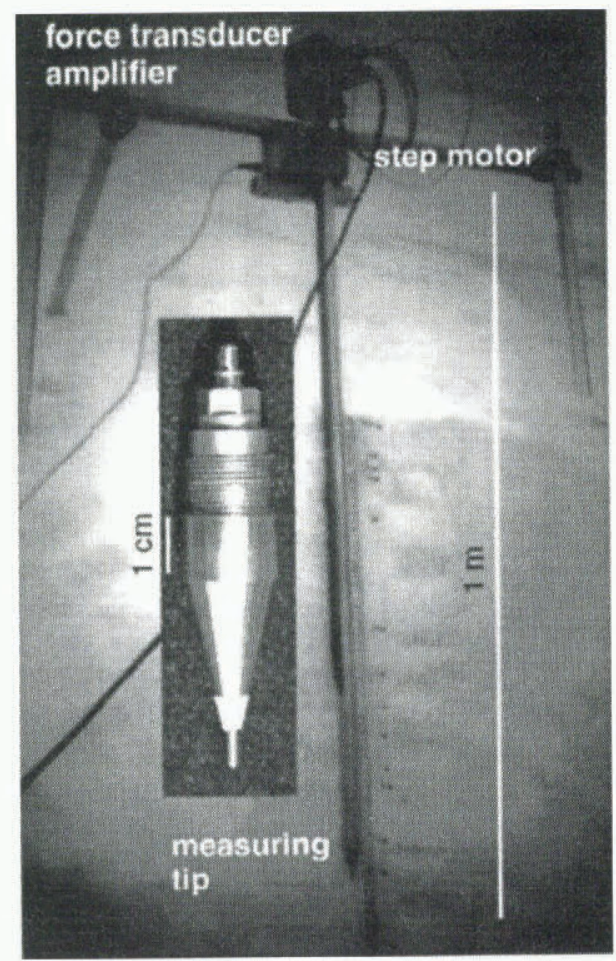

Fig. 1. Prototype penetrometer with the penetrometer tip, the cone and force transducer shown in the inset. The tip shown here is not flared, in contrast to the tip used for our experiments.

\section{DETECTION OF THIN LAYERS FROM PENE- TROMETER RESISTANCE PROFILES}

Tests of the prototype penetrometer's ability to detect thin layers were conducted both in a controlled laboratory setting and in the field.

In the laboratory, thin sheets of foam separated by an air layer (to simulate weak layers) were used to determine the minimum-size layer that could be detected by the penetrometer. An artificial material was used instead of snow so that layer thickness and resistance could be controlled. The layer was constructed by separating two polyurethane foam sheets $(2,5$ or $10 \mathrm{~mm}$ thick) from each other with an aluminum sheet of $1-10 \mathrm{~mm}$ thickness. The aluminum sheet contained a central hole which created an air layer between the foam sheets. Aluminum sheets, again containing through holes for the penetrometer, were placed on the top and bottom of the foam/aluminum stack and screwed together. The different thickness of the PUfoam layers causes a variable bending under load. The recognition of the thin layers is therefore more difficult, because the penetration resistance becomes smeared and does not drop to zero. A thicker layer of foam bends less when the penetration force is applied and the thinner layers of air can be discriminated. The result for $11 \mathrm{~mm}$ thick foam layers and a $2 \mathrm{~mm}$ thick air layer is shown in Figure 2. The penetration resistance does not reduce over a width of $2 \mathrm{~mm}$. The minimal value is $0.013 \mathrm{MPa}$, and the 


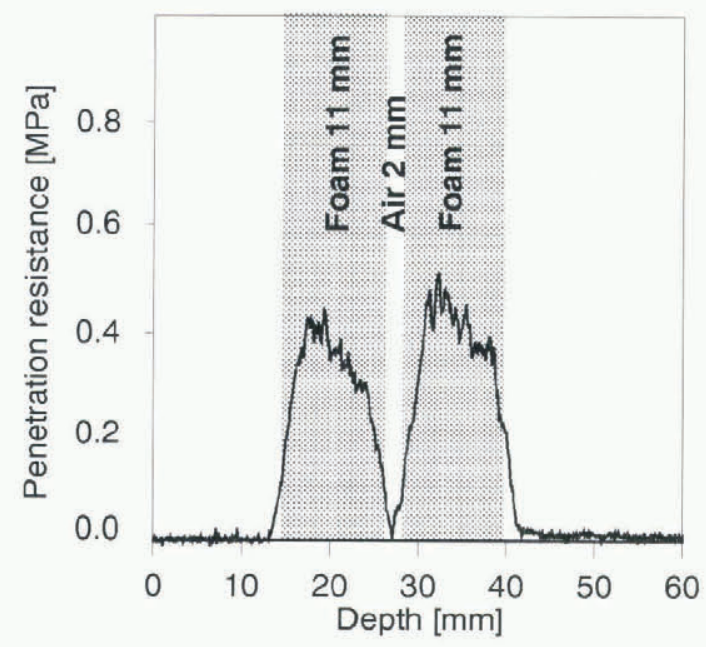

Fig. 2. Test measurements in polyurethane foam. The thickness of the foam layers is $11 \mathrm{~mm}$ separated by a $2 \mathrm{~mm}$ air layer.

mean value is around $0.05 \mathrm{MPa}$. The air layer can be seen completely (resistance $0.00 \mathrm{MPa}$ ) when the layer is more than 1.3 times thicker (air layer thicker than $7 \mathrm{~mm}$ ) than the length of the measuring tip.

In the field, thin layers detected from penetrometer resistance profiles were compared to the stratigraphic layering of the snow as determined from microphotographs of surface sections of dimethylphtalate cast samples taken adjacent to the profile (Fig. 3). The tests were conducted on 16 January 1996 on the north-facing slope of Totalphorn (Switzerland) at $2460 \mathrm{~m}$ a.s.l. To prevent the tip from sliding on hard crusts, the measurements were made perpendicular to the slope. Three measurements were made with $200 \mathrm{~mm}$ spacing. Measurement variation was small and did not exceed an absolute deviation of $0.02 \mathrm{MPa}$, except at the top hard crust at a depth of $20 \mathrm{~mm}(0.1 \mathrm{MPa})$. To investigate the structure of the thin layers, two samples were taken adjacent to the penetra-

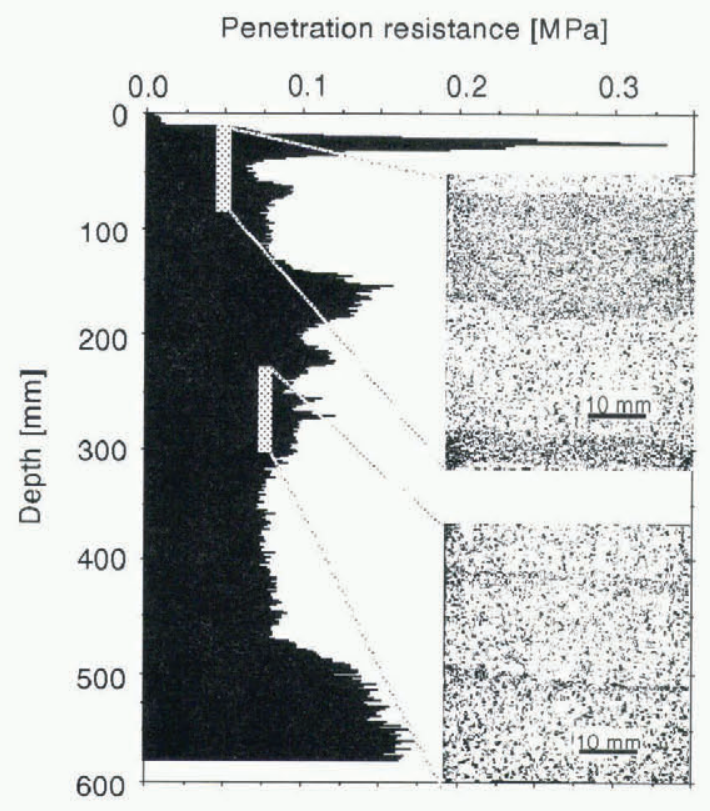

Fig. 3. Penetration resistance in a natural snowpack. The curve shows the averaged value of three measurements $20 \mathrm{~cm}$ apart. The thin hard and weak layers detected with the penetrometer are very visible in the sections. The surface sections show the harder and weaker layers. Black is ice.

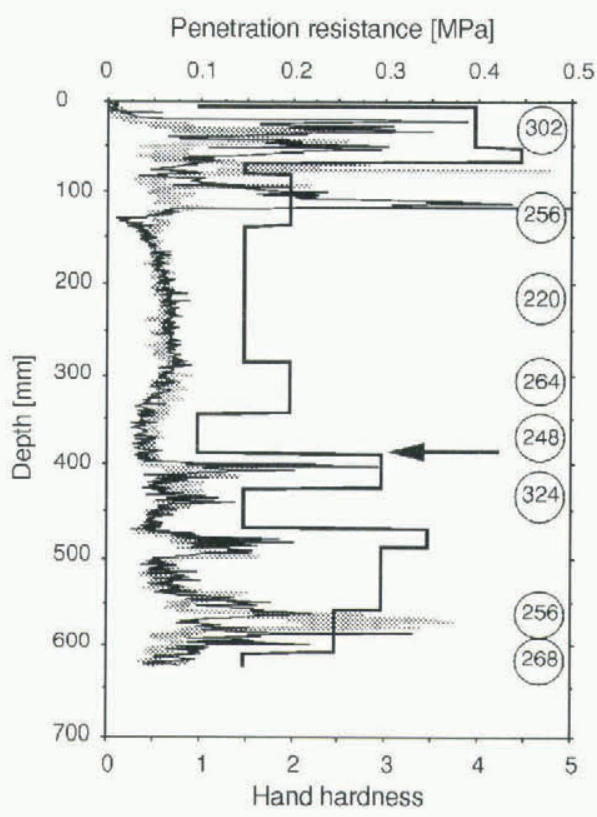

Fig. 4. Comparison of hand hardness (thick black line) (for scale see text) and two penetration measurements (thin black and thick grey line). The arrow marks the position where a slab could be released after the second jump with skis in a rutschblock test. The density of snow in $\mathrm{kg} \mathrm{m}^{-3}$ is noted on the right side of the drawing.

tion tests. These samples were cast in dimethylphtalate and surface sections cut. The surface sections show the different layers clearly. Especially noticeable was the $20 \mathrm{~mm}$ thick weaker layer between the hard crusts near the top of the profile. Only a few, millimeter-thick, hard crusts were noticeable between 240 and $280 \mathrm{~mm}$ snow depth.

\section{COMPARISON OF HAND HARDNESS AND PENE- TRATION RESISTANCE}

The hardness of snow measured by hand was compared to the penetration resistance. The hand hardness was measured with a five-step scale (fist, four finger, one finger, pencil, knife). Hand hardness was chosen because thin layers of a few millimeters can be detected. The measurements were made at the Weissfluhjoch on a north-facing slope near a ridge on 12 April 1995. Two penetrometer measurements separated by a distance of $0.2 \mathrm{~m}$ were made, and the hand hardness was determined in between the penetrometer measurements. The density of the snow varied between 220 and $320 \mathrm{~kg} \mathrm{~m}^{-3}$. The results are shown in Figure 4. The penetration resistance shows a very high variability in the top $130 \mathrm{~mm}$. The variability in hand hardness is much smaller. This top layer consisted of wind-blown snow with rounded grains. The layer from 130 to $400 \mathrm{~mm}$ consisted of small and solid faceted crystals. The penetration measurements were almost identical. The hand hardness shows a similar curve. However, the discontinuities shown in hand hardness are in fact slow changes in penetration resistance. The profile from 400 to $550 \mathrm{~mm}$, consisting of rounded and slightly faceted crystals, shows a good correspondence to the penetration resistances, except for the jump at $400 \mathrm{~mm}$. The hand hardness follows the values of penetration resistance up to $500 \mathrm{~mm}$ depth. The sudden decrease in penetration resistance below $500 \mathrm{~mm}$ and the increase between 550 and $600 \mathrm{~mm}$ was not detected by the hand hardness measure- 
ments. This layer again shows a high variability. Such layers with high variability seem to be very difficult to judge by hand hardness. The penetration resistance is not only a unique function of density but also of the bonding strength. The layer at the top of the profile $(0-60 \mathrm{~mm})$ has a similar density as the one at $420-480 \mathrm{~mm}$ of about $300 \mathrm{~kg} \mathrm{~m}^{-3}$. However, the top layer, consisting of rounded grains, has a much higher penetration resistance than the layer at 420 $480 \mathrm{~mm}$ which consists of slightly faceted grains.

\section{COMPARISON OF TENSILE STRENGTH AND PENETRATION RESISTANGE}

The mechanical significance of penetration resistance measurements was evaluated by comparing them to the tensile strength (determined by using a centrifuge). Measurements of density, tensile strength and penetration resistance for natural and sieved snow were compared to each other. The samples used for tensile strength measurements were each $58 \mathrm{~mm}$ in diameter and $180 \mathrm{~mm}$ in length. A small notch was made in the middle of each sample to create a well-defined stress-concentration plane. The penetration resistance of the tensile samples was found by penetrating the snow surrounding the sample. Where possible, multiple penetration tests were taken around the tensile sample. The values for these tests were averaged and the standard deviation calculated.

Comparisons between bulk density using tensile strength and penetration resistance are shown in Figure 5. The relationship between density and tensile strength breaks down at densities greater than $450 \mathrm{~kg} \mathrm{~m}^{-3}$ and no well-defined relationship can be found (Fig. 5a). These are sieved samples made of strongly faceted and coarse (1$2 \mathrm{~mm}$ ) snow crystals. A comparison of bulk density with penetration resistance (Fig. 5b) has less scatter than the corresponding density/tensile strength comparison. Penetration resistance increases linearly above $300 \mathrm{~kg} \mathrm{~m}^{-3}$. Little variation in penetration resistance and tensile strength with density could be found below this limit for snow tested in the laboratory. In general, tensile strength compared to penetration resistance shows a linear correlation (Fig. 6). The far-outlying values are for the same samples which show up as anomalous in the density-tensile strength relationship.

\section{DISCUSSION}

Our preliminary evaluation of the new penetrometer shows that it is capable of detecting thin hard and weak layers. For layers with a thickness greater than about $3 \mathrm{~mm}$, the penetration resistance can be quantified so that it can be used to index the mechanical behavior of that layer. Our comparative tests between penetration resistance and tensile strength are not a good indicator of the penetrometer's ability to provide mechanical-index information for snow. The comparative tests between penetration resistance and tensile strength and with density high-lighted two severe problems. First, it was very difficult to obtain homogeneous samples. The penetration resistance for the samples was an average of several measurements, whereas the tensile strength is determined for an isolated plane in the sample. This sample inhomogeneity (as detected by the penetrometer) is probably responsible for the large scatter. An effective comparison of penetrometer resistance with a mechanical property test org/10.3189/1998AoG26-1-107-111 Published online by Cambridge University Press
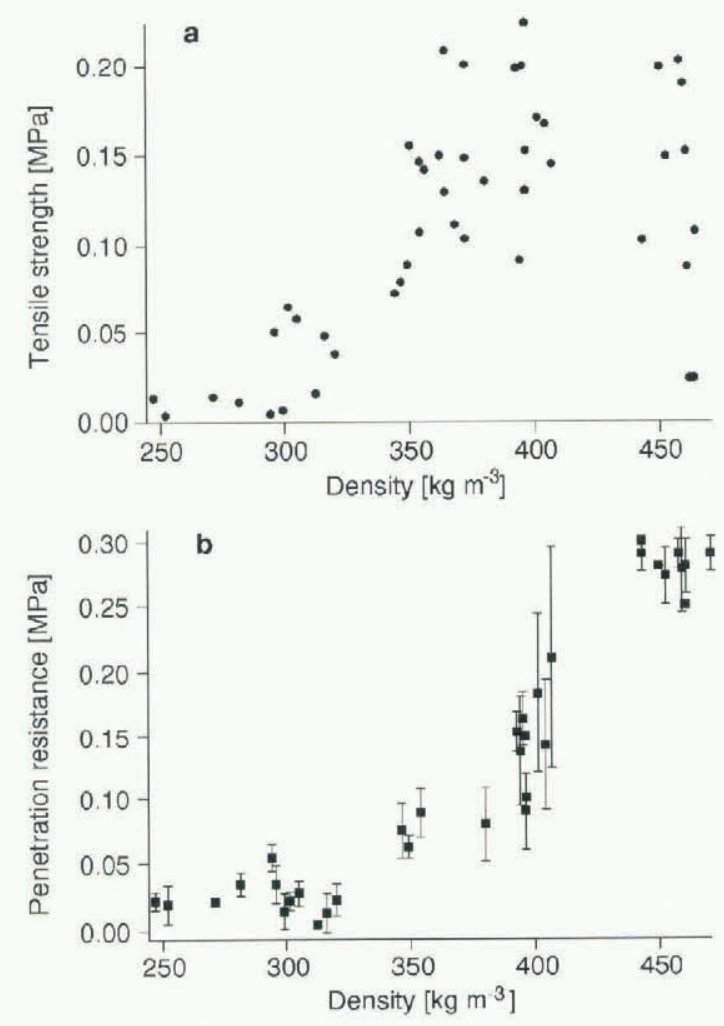

Fig. 5. Comparison between bulk density and tensile strength

(a) and between bulk density and penetrometer resistance (b). The bars indicate the variation of the penetration tests surrounding the samples taken for tensile-strength testing. They also show the variability of the snow within about a $10 \mathrm{~cm}$ spacing.

should require that the samples be very homogeneous. Penetrometer-resistance variance through a snow sample can give a good assessment of the degree of homogeneity. The second difficulty is that the centrifuge tensile-strength device has not been adequately examined to determine its ability to provide repeatable and accurate results. In these cases, compressive tests may be better suited.

The penetrometer-design features of high rigidity, constant speed penetration and high spatial resolution allow it to detect thin layers and snow microstructure to a higher degree than either the rammsonde or Pandalp. Several improvements are planned for future penetrometer designs, including: (i) a smaller included angle of the measuring tip

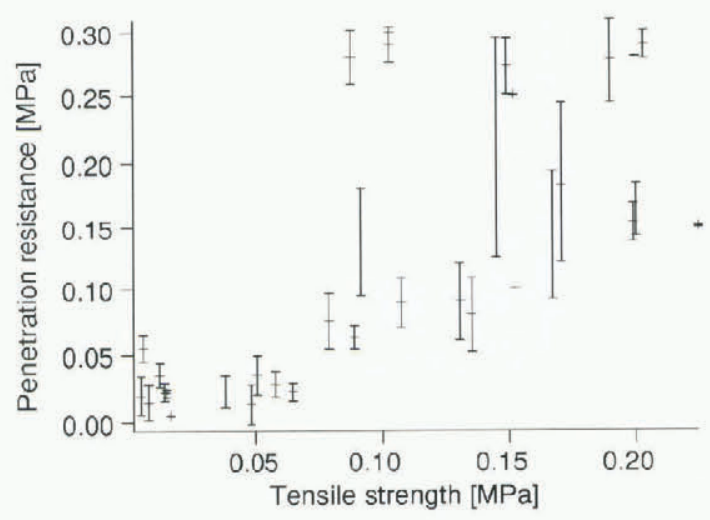

Fig. 6. Tensile strength and penetrometer resistance. The bars indicate the variation of the penetration tests surrounding the samples taken for tensile strength. 
and a smaller-diameter cone tip to produce less compaction and (ii) a thin-blade tip to further reduce the tip thickness $(1.5 \mathrm{~mm})$. The optimal diameter of the conical measuring tip and under what conditions a blade or cone tip are desirable are not yet completely clear. A compromise between structural resolution and penetration force must be sought. The electronic noise should be reduced, because it is well above the detection limit of the force sensor. A difficult problem is the insertion and tightening of the measuring tip into the cone. Some of these problems have already been solved in a newer prototype.

The interpretation of penetrometer-resistance profiles in snow is at its start. Initial efforts indicate that it may be possible, through signal analysis, to use penetration resistance to index mean bond strength, obtain internal structural information and to some degree determine grain-size and spacing. These measurements combined with a visual assessment of snow-grain shape and morphology may provide a way forward to classifying snow more accurately and reducing the scatter of measurements on the physical properties of snow.

\section{ACKNOWLEDGEMENTS}

We thank J. Baselmans and H. Utelli for help in the field, and W. Caviezel and G. Klausegger for construction of the device.

\section{REFERENCES}

Abe, O. 1991. [A prototype of fiber optic snow layer sonde.] Seppyo, J. Jpm. Soc. Snow Ice, 53 (1), 1-9. [InJapanese with English summary.]
Bader, H., R. Haefeli, E. Bucher, J. Neher, O. Eckel and C. Thams. 1954. Snow and its metamorphism. SIPRE Transl. 14.

Bradley, C. C. 1966. The snow resistograph and slab avalanche investigations. International Association of Scientific Hydrology Publication 69 (Symposium at Davos 1965 - Scientific Aspects of Snow and Ice Avalanches), 251-260.

Bradley, C. C. 1968. The resistograph and the compressive strength of snow. 7. Glaciol., 7 (5l), 499-506.

Brown, R. L. and K.W. Birkeland. 1990. A comparison of the digital resistograph with the ram penetrometer. In A Merging of Theory and Practice, International Snow Science Workshop, 9-13 October 1990, Bigfork, Montana. Proceedings, 19-30.

Dowd, T. and R. L. Brown. 1986. A new instrument for determining strength profiles in snow cover. f. Glaciol., 32(111), 299-301.

Föhn, P. M. B. 1993. Characteristics of weak snow layers or interfaces. In Armstrong, R., ed. ISSW'92. A Merging of Theory and Practice. International Snow Science Workshop, 4 \& October 1992, Breckenridge, Colorado. Proceedings. Denver, CO, Avalanche Information Center, 160-170.

Fukue, M. 1979. Mechanical performance of snow under loading. Tokyo, Tokai University Press.

Gubler, H. U. 1975. On the Rammsonde hardness equation. International Association of Hydrological Sciences Publication 114 (Symposium at Grindelwald 1974 - Snow Mechanics), 110-121.

Huang, A. B., M.Y. Ma and J. S. Lee. 1993. A micromechanical study of penetration tests in granular material. Mech. Mater., 16 (1-2), 133-139.

Johnson, J. B. and M. Schneebeli, 1997. Snow strength penetrometer. United States Patent Application, 4 May 1997.

Meigh, A. C. 1987. Cone penetration testing: methods and interpretation. London, Butterworths. Construction Industry Research and Information Association.

Navarre, J.-P., A. Taillefer, R. Gourves and E. Flavigny. 1994. Le "PANDA Neige". Neiges et Avalanches 66, 8-14.

Schaap, L. H. J. and P. M. B. Föhn. 1987. Cone penetration testing in snow. Can. Geotech. 7., 24(3), 335-341.

St. Lawrence, W. and C. C. Bradley, 1973. Comparison of the snow resistograph with the ram penetrometer. F. Glaciol., 12 (65), 315-321.

Vogel, F., 1995. Schneeprofilmesssonde. German Patent Office Report DE 195 $03017 \mathrm{Al}$. 